\title{
The study on wavelet coefficient behavior of simultaneous fault on the hybrid between overhead and underground distribution system
}

\author{
Chaichan Pothisarn, Chaiyan Jettanasen* \\ ${ }^{a}$ Faculty of Engineering, King Mongkut's Institute of Technology Ladkrabang, Bangkok, Thailand
}

\begin{abstract}
This paper proposed the study on behaviour and characteristic of wavelet coefficient in case of simultaneous fault occurrence on hybrid transmission system. The ATP/EMTP software has been used to simulate 115-km hybrid transmission line that modelled after on part of PEA distribution system. The case study system is $40 \mathrm{~km}$ distribution line with overhead line on first $20 \mathrm{~km}$ section and underground cable on the second half. The Discrete Wavelet Transform (DWT) has been used to analyse fault signal. Various factor that can affect system characteristic such as inception angle, location, and type of fault has been taken into consideration. The result shown the significant change in coefficient of high frequency component when simultaneous fault occurs compared to single fault especially in hybrid distribution system when fault occur on both overhead and underground cable, thus result in problematic analysis of coefficient and complexity in design suitable algorithm. This change in system characteristic must be taken into consideration when develop protection system in order to achieve the satisfactory performance with even more complex power system in the future.
\end{abstract}

Keywords: Distribution System, Fault, Overhead line, Underground cable, Wavelet transform

\section{Introduction}

In the recent decade, economic and population in developing country including Thailand has experience a significant growth with rapid industrialize from agriculture society and long-life expectancy from better quality of life. This trend results in expanding of electrical infrastructure, especially in transmission and distribution network in order to keep up with increasingly electrical demand. However, the further system has expanded, the complexity of the system also increases with many part of distribution line using both overhead lines and underground cables. This can affect performance of conventional protection system or the fault diagnosis algorithm that based on wavelet transform due to signal under fault condition give out different characteristic wherever fault occur on overhead line or underground cable.

The discrete wavelet transforms (DWT) has been widely used in power system to analyse transient phenomenal especially in fault diagnosis due to the remarkable feature that can extract high frequency component from the signal [1]-[2]. For the hybrid distribution line many researches have been study and proposed the algorithm that can be applied to such a system such as fault location algorithm based on travelling wave theory [3]-[4], fault classification [5] etc. The characteristic analysis of simultaneous fault on high voltage transmission line using wavelet transform has been discussed [6] In [7], the study has present fault location method that can applied on both single and simultaneous fault in distribution network using fuzzy logic and machine learning.

From the literature review discuss above, it can be seen that many researches has present fault

\footnotetext{
* Manuscript received August 4, 2018; revised March 14, 2019.

Corresponding author. E-mail address: chaiyan.je@kmitl.ac.th.

doi: $10.12720 /$ sgce.8.3.367-371
} 
diagnosis techniques on system that simultaneous fault occurs or in case of fault occurrence on hybrid system. However, few researches have done study on the behaviour of DWT coefficient when simultaneous fault occurs in the hybrid system. So, this paper proposed an analysis of DWT coefficient behaviour when simultaneous fault occurrence on hybrid distribution line that consist of both overhead lines and underground cable. The ATP/EMTP software has been used to simulate fault characteristic in various case and its signal has been analyse using DWT. The result from the study can be used to further improve performance of distribution line protection system in the future.

\section{Simulation}

Simultaneous fault on hybrid distribution line has been simulate in this research using ATP/EMTP software. The system under study is modelling after part of Provincial Electricity Authority's (PEA) 115-

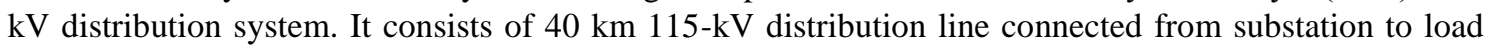
centre with first $20 \mathrm{~km}$ section is overhead line and last $20 \mathrm{~km}$ section is underground cable as shown in Fig. 1.

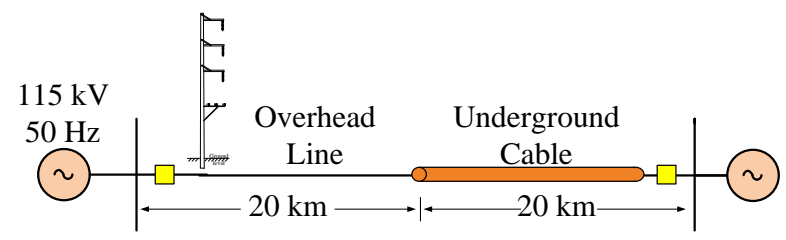

\section{Substation \\ bus}

Load bus

Fig. 1. Simplified diagram of hybrid distribution system

The example of current signal obtain from ATP/EMTP software can be shown in Fig. 2. It shown simultaneous fault signal in case of first fault on distribution line, based on substation bus as reference, is single phase (phase A) to ground fault located at $20 \%$ of distribution line and the second fault is double line (phase B and phase C) fault located at $40 \%$ of distribution line both measured from substation side. It can be seen from the signal that after fault occurring at 0.04 second, the waveform has abrupt changes in all of the phase and can be perceived as three-phase fault even though it single phase to ground and double line fault that occur simultaneously. In order to address such an issue, the comparative study on both single and simultaneous fault characteristic on hybrid distribution line must be taken into consideration.
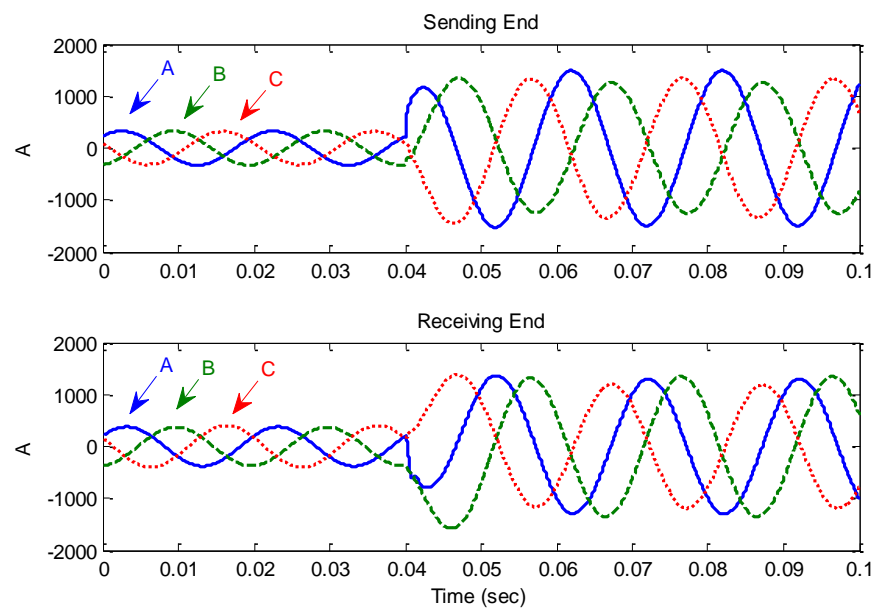

Fig. 2. Current signals in case of simultaneous fault between single phase to ground and double line fault located at $20 \%$ and $40 \%$ of distribution line. 


\section{Result}

The fault signal obtain from ATP/EMTP software on both substation and load bus will then analyse by using DWT. The mother wavelet Daubechies $4(\mathrm{db} 4)$, which suitable for analysed transient signal in power system, has been used to extract high frequency component into 5 scales. The analysed signal on both substation and load bus using DWT is shown in Fig. 3.
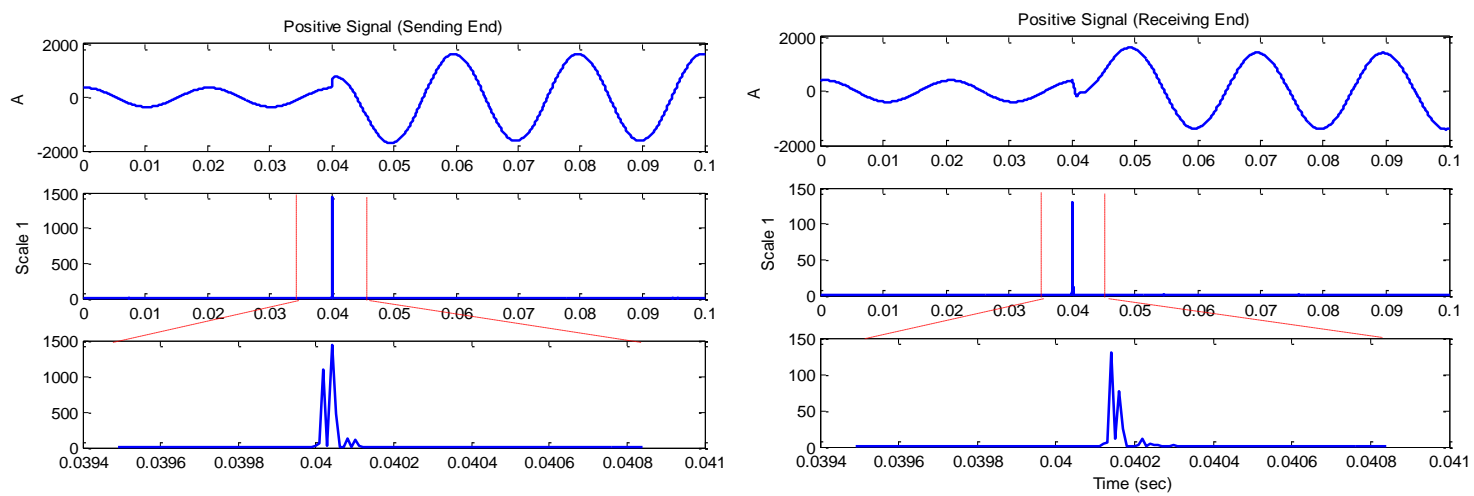

(a)

(b)

Fig. 3. High frequency component of fault signal using DWT: (a) Substation bus (b) Load bus.

\subsection{Single fault}

In case of single fault in hybrid distribution line, the research used single phase to ground fault (phase A) and varying its location from $10 \%$ to $90 \%$ of distribution line with $10 \%$ interval using substation bus as reference as shown in Fig. 4. Form the figure, it can be seen that coefficient of high frequency component when measure from load bus terminal of distribution line is higher than first half of distribution line that consist of overhead line. This direct result from type of distribution line when fault occur on underground cable it generated more coefficient than overhead lines. However, signal obtain from substation bus does not change significantly due to the travelling wave has moving through different type of conductor.

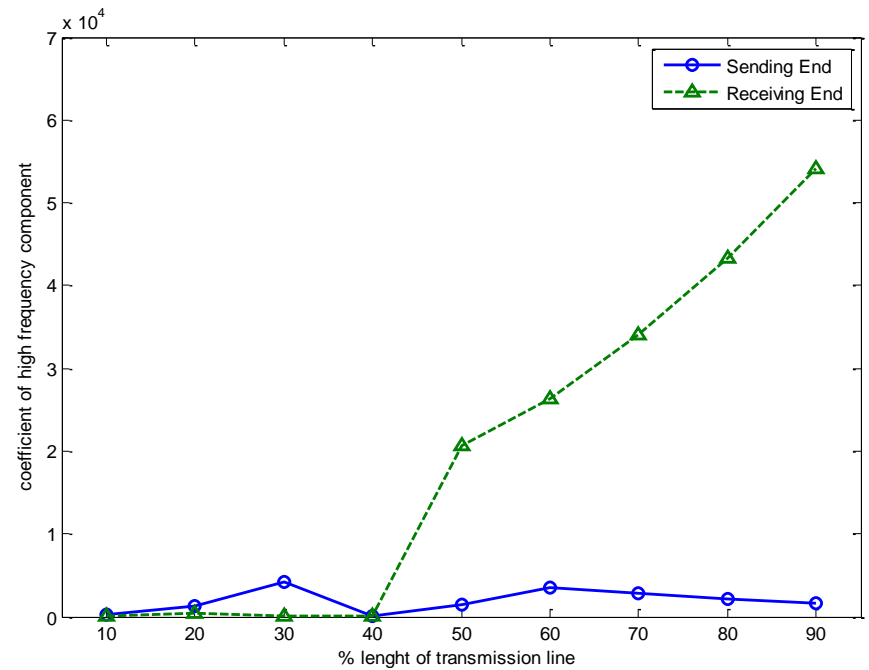

Fig. 4. Coefficient of high frequency components in case of single fault 


\subsection{Simultaneous fault}

For the simultaneous fault in hybrid distribution line, this research proposed comparative study on two case studies as followed; Case I is single phase to ground fault (phase A) occur at $20 \%$ of distribution lines and double line fault (phase B and phase C) has been varied from $10 \%$ to $90 \%$ of distribution line with $10 \%$ interval using substation bus as reference. Case II is similar to previous case except the location of single phase to ground fault (phase A) has been occur at $80 \%$ of distribution lines. The behaviour of coefficient can be illustrated in Fig. 5 (a) and (b) respectively.

From the figure, it can be seen that behaviour of coefficient at overhead line and underground cable does not change significantly with fault location. In case I with fix location of first fault near substation bus, the maximum coefficient at substation bus is higher than load bus. In case II, the result reveals the similar trend compare with previous case, but the maximum coefficient obtain from load bus is higher than substation bus due to fixed location of single line to ground fault that contribute significant to coefficient value on nearest bus.

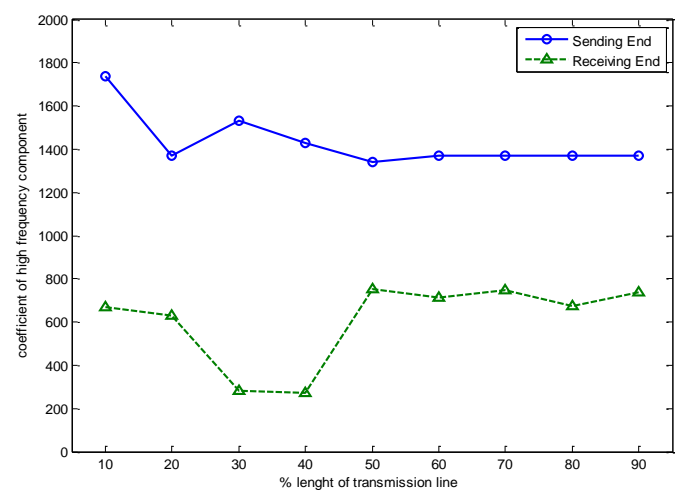

(a)

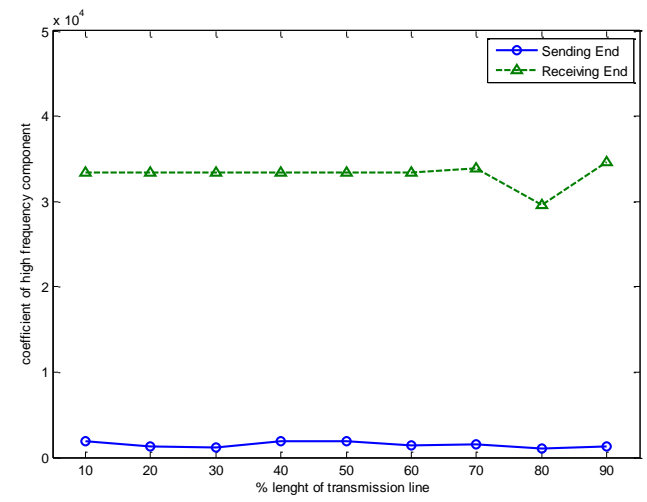

(b)

Fig. 5. Coefficient of high frequency components in case of simultaneous fault (a) Varied location of first fault (b) Varied location of second fault.

\section{Conclusion}

This paper proposed an analysis on hybrid distribution system under simultaneous fault using DWT. The coefficient of high frequency component reveals different characteristic which under influence of factor such as fault location (distance from bus that consist of data recorder), fault type, types of conductor (overhead lines or underground cable).

The results reveal that the behaviour of coefficient from DWT that it has unique characteristic depend on its location, fault types and types of conductor (overhead lines or underground cable). In case of single fault, the varying of fault location shown that coefficient in underground cable is higher than overhead line. In case of simultaneous fault, the maximum coefficient obtain from substation bus or load bus depends on fixed location of fault that located near bus that has data recorder. However, location of second fault does not have significant impact on wavelet coefficient.

The analysis on coefficient value that proposed in this research is a significant part to design fault location, detection and classification algorithm that based on DWT. This analysis can be applied to further improve protection system performance under much more complexity in the future.

\section{Acknowledgements}

The authors wish to gratefully acknowledge financial support for this research from Faculty of Engineering, King Mongkut's Institute of Technology Ladkrabang Research fund (No. 2558-014-01013), Thailand. 


\section{References}

[1] Patel TK, Panda PC, Swain SC, Mohanty SK. A fault detection technique in transmission line by using discrete wavelet transform. In: Proc. of 2017 Second International Conference on Electrical, Computer and Communication Technologies (ICECCT), 2017:1-6.

[2] Masood B, Saleem U, Anjum MN, Arshad U. Faults detection and diagnosis of transmission lines using wavelet transformed based technique. In: Proc. of 2017 IEEE Jordan Conference on Applied Electrical Engineering and Computing Technologies (AEECT), 2017:1-6.

[3] Chen P, Wang K. Fault location technology for high-voltage overhead lines combined with underground power cables based on travelling wave principle. In: Proc. of 2011 International Conference on Advanced Power System Automation and Protection, 2011:748-751.

[4] Han J, Crossley PA. Fault location on mixed overhead line and cable transmission networks. In: Proc. of 2013 IEEE Grenoble Conference, 2013:1-6.

[5] Klomjit J, Ngaopitakkul A. Fault classification on the hybrid transmission line system between overhead line and underground cable. In: Proc. of 2017 Joint 17th World Congress of International Fuzzy Systems Association and 9th International Conference on Soft Computing and Intelligent Systems (IFSA-SCIS), 2017:1-6.

[6] Pothisarn C, Ngaopitakkul A. Analysis of Characteristics Using Wavelet Transform for Simultaneous Faults in Electrical Power System. In: Proc. of 2012 Third International Conference on Innovations in Bio-Inspired Computing and Applications, 2012:93-97.

[7] Majidi M, Amoli ME, Fadali MS. A Novel Method for Single and Simultaneous Fault Location in Distribution Networks. IEEE Transactions on Power Systems, 2015, 30(6): 3368-3376. 